\title{
Science and society test VIII: The arms race revisited
}

\author{
David W. Hafemeister \\ Physics Department, California Polytechnic University, San Luis Obispo, California 93407
}

\begin{abstract}
Approximate numerical estimates are developed in order to quantify a variety of aspects of the arms race. The results of these calculations are consistent with either direct observations or with more sophisticated calculations. This paper will cover some of the following aspects of the arms race: (1) the electromagnetic pulse (EMP); (2) spy satellites; (3) ICBM accuracy; (4) NAVSTAR global positioning satellites; (5) particle and laser beam weapons; (6) the neutron bomb; and (7) war games.
\end{abstract}

\section{INTRODUCTION}

The initial paper in this series ${ }^{1}$ dealt with a number of aspects of the arms race such as the Spartan (high altitude) and Sprint (low altitude) and antiballistic missile (ABM) systems; the tradeoff between accuracy and yield, and its impact on superhardening missile sites and on multiple independently targetable re-entry vehicles (MIRV); cost-exchange ratios; and other issues. Almost a decade has passed and the arms race continues. Because of advances in technology, the arms race has become more of a qualitative (new technologies) rather than a quantitative (numbers of launchers) arms race. The newer technologies of cruise missiles and the mobile MX missiles have exacerbated the issue of "adequate" verification that is one of the touchstones of arms control agreements. Further technological advances in the areas of increased missile accuracy through the use of NAVSTAR satellites, laser and particle beam weapons, the neutron bomb, and other technologies could create additional layers of political and technological uncertainty.

It is not the purpose of this paper to discuss the broader issues of war and peace such as action-reaction arms escalation, institutional pressures to increase armaments, a desire to have the same armaments as ones opponent (mirror imaging), the historical factors which determine each nation's insecurities about its national security, a description of the various arms control treaties, the difference between sufficiency and parity, the connection between horizontal, and vertical proliferation, and the tradeoffs between offensive-defensive, first-strike-second-strike, tactical-strategic weapons, and other factors. These issues have been widely discussed by numerous authors ${ }^{2}$ over the years; recently Schroeer and Dowling ${ }^{3}$ have compiled an extensive reference list on these broader subjects as well as the technical ones. The scope of this paper will not focus on these very important (often subjective) issues, but, rather, it will deal with some of the basic physics (objective and calculable) factors involved in the development of some of the advanced technologies.

Recently, Wollett" in an article entitled, "Physics and Modern Warfare: The Awkward Silence,' has pointed out that

the typical general education course in physics or physical science offers the student a misleading impression of the interaction of science and society. Such courses tend to stress the benefits to man which follow progress in science (as well as the intellectual excitement and intrinsic beauty of pure science). Little mention is made of the serious problems man is presently faced with, problems directly related to progress made in science.

This paper and its predecessor are an attempt to respond to this challenge. Our goal is to encourage a dispassionate methodology for analyzing the technical aspects of these problems which emphasizes the basic science involved without using overly sophisticated mathematics and physics. Only by first considering these difficult technical problems can we hope to make some progress towards developing viable solutions. Our calculations on the physics of the arms race will use only widely accepted numerical parameters; our results agree with either direct observation or with more complex calculations. In particular, this paper will quantify the following technical aspects of the arms race:

I. Electromagnetic pulse (EMP). The range (km), $E$ field strength $(\mathrm{V} / \mathrm{m})$, frequency spectrum $(\mathrm{Hz})$, and radiative mechanism.

II. Spy satellites. The size of objects and limits to resolution.

III. ICBM accuracy. Uncertainties in parameters and the hardness of missile sites.

IV. NAVSTAR global positioning satellites. Guidance by delay times and by Doppler shifts.

V. Particle and laser beam weapons. Energy deposition, beam current, angular resolution, burning a hole in the atmosphere, and diffraction broadening.

VI. Neutron bomb. The enhanced neutron yield and reduced blast area.

VII. War games. The lethality parameter $K$, Minuteman vulnerability, and the Richardson model.

\section{ELECTROMAGNETIC PULSE (EMP)}

The command, control, the communication $\left(C^{3}\right)$ systems which control the U.S. strategic forces can be vulnerable to the large electromagnetic pulses ${ }^{5}(E \simeq 25000 \mathrm{~V} / \mathrm{m})$ that are created by high-altitude (100-500 km) or low-altitude (0-2 $\mathrm{km}$ ) bursts of nuclear weapons. This vulnerability has been perceived by both the doves and hawks on arms control matters as creating a possible instability in the arms race. If a country perceives that the use of its strategic forces could be negated by the EMP so that it could not command and control its missiles, then this country might be tempted to adopt a "launch on warning" policy so that it would use its weapons rather than lose them to a preemptive first strike. The situation is not as unstable as I have characterized it because both nations have hardened their systems to partially withstand the EMP and both nations have viable, 
second-strike missiles based on submarines that are not vulnerable to a first strike. However, the perception of vulnerability in the land-based leg of the strategic triad (landsea-air) can create pressures for a "now or never," launchon-warning response. Since some of the $C^{3}$ facilities, such as the Air Force's Looking Glass command post in the sky, are more vulnerable than some of the strategic forces that they are intended to direct, and since the U.S. land-based missiles could be vulnerable to an EMP attack, it is clear that the EMP can affect military policy.

A brief discussion of the mechanism that creates the EMP is given below: In an explosion of a nuclear weapon, many of the fission fragments are created in an excited state. Since these excited states have energies of $1 \mathrm{MeV}$ or more, their lifetimes are much less than the risetime of the explosion (about $10 \mathrm{~ns}$ ); the de-excitation gamma rays are emitted promptly. These prompt gamma rays interact with air molecules and create forward scattered Compton electrons which constitute an energetic (about $1 \mathrm{MeV}$ ), negative current flowing radially outward from the weapon (see Fig. 1). In order to have a large EMP, it is necessary to remove the spherical symmetry around the nuclear weapon. At low altitudes above the Earth, a net dipole moment is created because the Compton electrons are in the form of a hemisphere rising above the Earth; the asymmetry of the rising, charged hemisphere creates the EMP. At high alti-

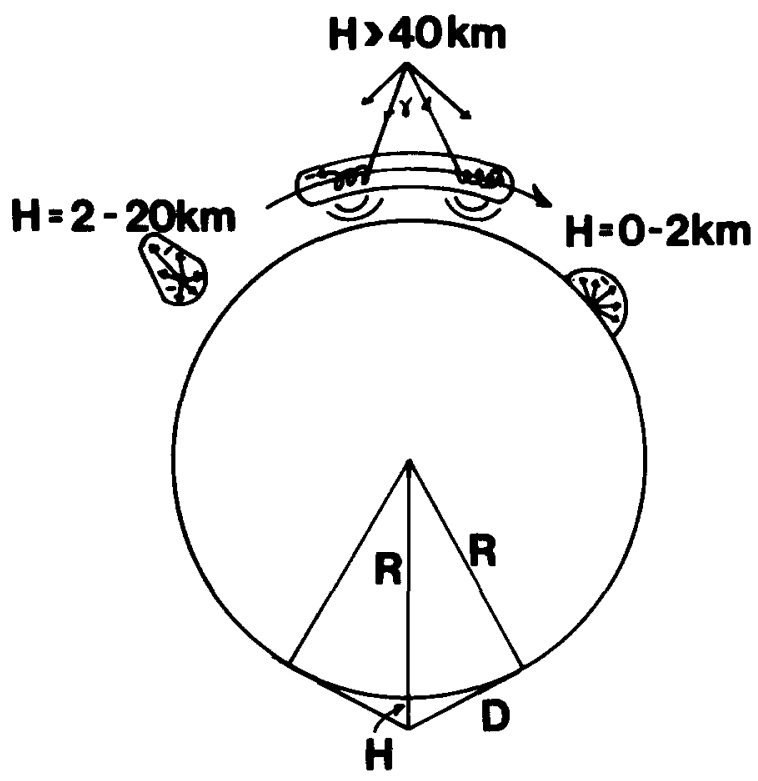

Fig. 1. Electromagnetic pulse (EMP). During a nuclear explosion gamma rays are emitted promptly from the excited states of the fission fragments; these prompt gamma rays transfer their energy to electrons in air molecules by the Compton scattering process. The EMP is generated by these relativistic electrons by several mechanisms which depend on the altitude $\boldsymbol{H}$ of the nuclear explosion above the Earth. A surface blast at low altitudes $(H=0-2 \mathrm{~km})$ causes a hemispherical, rising Compton current which creates a large net vertical dipole current. An air burst $(H=2-20$ $\mathrm{km}$ ) creates a small net vertical dipole moment because the asymmetrical density of air which varies exponentially with height. A high-altitude $(H>\mathbf{4 0} \mathrm{km})$ explosion creates Compton electrons that revolve in circles around the Earth's magnetic field lines; the centripetal acceleration of the Compton electrons produces EMP radiation. Because the Compton electrons are relativistic, the EMP radiation from the individual electrons have a partial degree of coherence which can give very large $E$ fields of greater than $25000 \mathrm{~V} / \mathrm{m}$. The high-altitude EMP pulse can illuminate wide areas of the Earth's suface; the range of the EMP is determined by its line-of-sight distance, $D=(2 R H)^{1 / 2}$, where $R$ is the radius of the Earth. tudes, the symmetry is broken because the air density varies exponentially with height above the Earth so that the Compton electrons are created asymmetrically and a net dipole moment is created. The electrons created from the very high altitude bursts (above the atmosphere) follow a helical path about the Earth's magnetic field lines in the very thin upper atmosphere; the centripetal acceleration of these Compton electrons creates the EMP. In addition, the $\mathbf{x}$ rays following a nuclear explosion can also produce EMP effects by ionizing the atmosphere and momentarily affecting the magnetic field configuration of the Earth.

\section{A. Range of EMP}

Assume that sufficient megatonnage is available for the EMP pulse, and that one must only consider line-of-sight geometry when considering covering the US with the EMP pulse. What is the height $H$ of the blast that is necessary to cover $50 \%$ and $100 \%$ of the U.S.?

Answer: The extremum distance from the nuclear detonation to the ground is obtained from a right triangle which has one side as the distance $D$, the other side the radius $R$ of the Earth at the location in question, and the hypotenuse extends from the center of the Earth to the blast $(H+R)$ (see Fig. 1). It follows that

$$
R^{2}+D^{2}=(H+R)^{2} \simeq R^{2}+2 H R,
$$

when $H<R$. From this we obtain the height of the EMP blast to cover all the U.S.:

$$
H=D^{2} / 2 R=\left(2500 \mathrm{~km}^{2}\right)^{2} / 2(6400 \mathrm{~km})=500 \mathrm{~km} \text {. }
$$

For the case of $50 \%$ of the U.S., $D=1800 \mathrm{~km}$ and $H=250$ $\mathrm{km}$.

\section{B. Strength of the EMP fields}

What is the approximate average ( $\mathrm{rms}) E$ field generated by the EMP pulse at a location $D=1000 \mathrm{~km}$ from the blast? Assume the following: (1) 1-Mt weapon contains $10^{15}$ cal or $4.2 \times 10^{15} \mathrm{~J} ;(2)$ the prompt gamma rays constitute $0.3 \%$ of the total energy, they have an average energy of about $1 \mathrm{MeV}$, and they are emitted over the 10-ns risetime of the blast; and (3) about $0.6 \%$ of the gamma ray energy is converted into Compton electrons. (If each of the fission fragments emitted a 1-MeV gamma ray, and if $50 \%$ of these gamma rays were not absorbed by the materials of the weapon, then about $0.5 \%(1 \mathrm{MeV} / 200 \mathrm{MeV})$ of the energy of the weapon would be in the form of prompt gamma rays.)

Answer: The amount of energy available for the EMP pulse from the 1-Mt weapons is about

$$
\mathrm{UEMP}=\left(4.2 \times 10^{15} \mathrm{~J}\right)(0.003)(0.006)=7.6 \times 10^{10} \mathrm{~J} .
$$

This energy can be considered to be approximately evenly distributed in a spherical shell with a volume $4 \pi D^{2} T$ where $D$ is the distance from the site to the blast. The thickness $T$ of the EMP shell is the product of the speed of light and the time duration of the blast, or $T=\left(3 \times 10^{8} \mathrm{~m} / \mathrm{s}\right)\left(10^{-8} \mathrm{~s}\right)=3$ $\mathrm{m}$. Since $50 \%$ of the stored energy resides in the electric fields, we obtain

$$
\mathrm{UEMP} / 2=\left(\epsilon_{0} E^{2} / 2\right)\left(4 \pi D^{2} T\right)
$$

or

$$
\begin{aligned}
E & =\left(U E M P / 4 \pi \epsilon_{0} T\right)^{1 / 2} / D \\
& =\left(7.6 \times 10^{10} \times 9 \times 10^{9} / 3\right)^{1 / 2} / 10^{6}=15000 \mathrm{~V} / \mathrm{m} .
\end{aligned}
$$

A more sophisticated calculation of the $E$ field is carried 
out in Sec. I C below, but this approximate estimate is sufficient to show that the $E$ field can be quite large. The ener$\mathrm{gy} / \mathrm{cm}^{2}$ deposited on the semiconducting components used in $C^{3}$ is of the order of

$$
\left(7.6 \times 10^{10} \mathrm{~J}\right) /(4 \pi)\left(10^{8} \mathrm{~cm}\right)^{2}=6 \times 10^{-7} \mathrm{~J} / \mathrm{cm}^{2} .
$$

This flux of energy can be effectively multiplied by the area of powerlines, antennas, or missile bodies, and the resulting electrical transients can be sufficient to destroy many of the semiconducting devices.

\section{Frequency spectrum}

A fundamental calculation of the frequency and field strength distributions from a high-altitude burst involves a calculation of the magnitude of the Compton electronic charge and how this charge accelerates in the Earth's magnetic field. In order to do this we must consider the relativistic expression for the radiative power,

$$
P=e^{2} a^{2} \gamma^{4} / 6 \pi \epsilon_{0} c^{3},
$$

from an accelerated charge where $a$ is the acceleration and

$$
\gamma=1 /\left(1-v^{2} / c^{2}\right)^{1 / 2} \text {. }
$$

Using this relationship, what is the approximate magnitude of the $E$ field from a high-altitude, 1-Mt explosion, and what is the maximum frequency of the EMP spectrum? The magnitude of the $B$ field above the U.S. is about $0.6 \mathrm{G}$.

Answer: Because the duration of the explosion is about $10^{-8} \mathrm{~s}$, the maximum frequency possible for the EMP is about $100 \mathrm{MHz}$, but in practice it is considerably lower. Since the Compton electrons have a kinetic energy of about $1 \mathrm{MeV}=2 m_{0} c^{2} ; \gamma=3$ and $v / c=0.94$. The radius of gyration $r$ of the Compton electrons in the Earth's field of $0.6 \mathrm{G}$ is

$$
\begin{aligned}
r & =\frac{\gamma m_{0} v}{e B}=\frac{3\left(9.1 \times 10^{-31} \mathrm{~kg}\right) 0.94\left(3 \times 10^{8} \mathrm{~m} / \mathrm{s}\right)}{\left(1.6 \times 10^{-19} \mathrm{C}\right)\left(0.6 \times 10^{-4} \mathrm{~T}\right)} \\
& =80 \mathrm{~m} .
\end{aligned}
$$

The frequency of radiation associated with this motion is

$$
\omega=v / r=0.94\left(3 \times 10^{8} \mathrm{~m} / \mathrm{s}\right) / 80 \mathrm{~m}=3.5 \mathrm{Mrad} / \mathrm{s} \text {, }
$$

or

$$
f=\omega / 2 \pi=0.56 \mathrm{MHz} \text {. }
$$

The approximate number of prompt gamma rays emitted from the 1-Mt explosion is

$$
\begin{aligned}
N_{\Gamma} & =\left(4.2 \times 10^{15} \mathrm{~J}\right) 0.003\left(\frac{1 \mathrm{MeV}}{1.6 \times 10^{-13} \mathrm{~J}}\right) /\left(\frac{1 \mathrm{MeV}}{\Gamma}\right) \\
& =7.9 \times 10^{15} \Gamma / \mathrm{Mt} .
\end{aligned}
$$

Since about $0.6 \%$ of this energy is converted to Compton electrons, the approximate initial number of Compton electrons produced is $N_{e}=0.006\left(7.9 \times 10^{25}\right)=4.7 \times 10^{23}$ electrons/ $\mathrm{Mt}$, or $75000 \mathrm{C} / \mathrm{Mt}$.

The initial centripetal acceleration for each Compton electron is about

$$
a=r \omega^{2}=80 \mathrm{~m}\left(3.5 \times 10^{6} / \mathrm{s}\right)^{2}=1.0 \times 10^{15} \mathrm{~m} / \mathrm{s}^{2} .
$$

The initial power radiated by this electron is

$$
\begin{aligned}
P & =e^{2} a^{2} \gamma^{4} / 6 \pi \epsilon_{0} c^{3} \\
& =\left(1.6 \times 10^{-19} \mathrm{C}\right)^{2}\left(1.0 \times 10^{15} \mathrm{~m} / \mathrm{s}^{2}\right)(3)^{4}\left(6 \times 10^{9}\right) /\left(3 \times 10^{8}\right)^{3} \\
& =4.6 \times 10^{-22} \mathrm{~W} .
\end{aligned}
$$

If the fields from the $N_{e}=4.7 \times 10^{23}$ Compton electrons added incoherently, the EMP radiated power would be only about

$$
\left(4.7 \times 10^{23}\right)\left(4.6 \times 10^{-22} \mathrm{~W}\right)=220 \mathrm{~W},
$$

which would not produce a very large $E$ field. However, since the wavelength of this radiation, $\lambda=c / f=540 \mathrm{~m}$, is much longer than the spatial thickness of the prompt radiation,

$$
T=c(10 \mathrm{~ns})=3 \mathrm{~m},
$$

and since the velocity of the Compton electrons is approximately $c$, the EMP electric fields are partially additive, or coherent. Let us initially assume that all $N_{e}$ electrons give coherent EMP radiation; a comparison of the field from this completely coherent situation can then be compared to the given value of about $25000 \mathrm{~V} / \mathrm{m}$ to determine the degree of coherence.

If the Compton electrons radiated coherently, the effective radiative power would be $\left(N_{e}^{2}\right) P=1.0 \times 10^{26}$ (similar to the radiative power of the sun!). The average value of the Poynting vector for this radiation [neglecting the $\sin ^{2}(\theta)$ distribution] is $P / 4 \pi D^{2}$ where $D$ is the distance from the closest Compton electrons to the site (perhaps an average effective value of $100 \mathrm{~km}$ ). From this the average $E$ field is given by

$$
\begin{aligned}
E & \cong\left(P / 4 \pi \epsilon_{0} c D^{2}\right)^{1 / 2} \\
& =\left[\left(1.0 \times 10^{26} \mathrm{~W}\right)\left(9 \times 10^{9}\right) /\left(3 \times 10^{8} \mathrm{~m} / \mathrm{s}\right)\left(10^{10} \mathrm{~m}^{2}\right)\right]^{1 / 2} \\
& =5.5 \times 10^{8} \mathrm{~V} / \mathrm{m} .
\end{aligned}
$$

Since this result is about $10^{4}$ times larger than the reported value of $2.5 \times 10^{4} \mathrm{~V} / \mathrm{m}$, we see that, on average, only about $0.01 \%$ of the Compton electrons must be totally coherent. As the Compton electrons loses energy, lower-frequency, longer-wavelength components are added to the EMP distribution, and the radiation becomes less coherent.

Rather large currents can be generated by the EMP. The voltage developed along the length of a $20-\mathrm{m}$ missile could be as much as $V=(25000 \mathrm{~V} / \mathrm{m})(20 \mathrm{~m})=500000 \mathrm{~V}$. Since the inductive impedance of a missile at $1 \mathrm{MHz}$ is about $Z=10 \Omega$, the current flowing along the surface of the missile could be as high as as

$$
I=V / Z=\left(5 \times 10^{5} \mathrm{~V}\right) /(10 \Omega)=50000 \mathrm{~A} \text {. }
$$

By coupling through various inductive and capacitive transfer impedances, this current can produce voltage transients on the center conductors of the cables in the missile on the order of 1-100 V. While this amount of voltage will only burn out the most sensitive semiconductors, it could upset the digital circuitry and nullify its computer logic. Much larger voltages could be developed on these logic elements if one considers the voltages developed on the powerlines to the missile sites, but is is possible to overcome these difficulties by shielding and hardening the electronics with filter circuits and fiber optics.

\section{SPY SATELLITES}

The high resolution ${ }^{6}$ obtainable with today's reconnaissance satellites has both a stabilizing and a destabilizing effect on the arms race. Since both sides are now capable of counting and monitoring the intercontinental ballistic missiles (ICBM) of the other side, both sides should be less prone to be driven by "worst case analysis" to build additional systems to counter feared "missile gaps." Because of the satellites and other national technical means, many felt 
that the SALT treaties could be verified "adequately" to ensure compliance by the U.S.S.R. On the other hand, one could argue that accurate reconnaissance from spy satellites would allow a nation to consider a preemptive first strike if the data showed that they might succeed in such an act. On balance, the spy satellites may well be more stabilizing then destabilizing to world peace; President Johnson commented on this aspect in 1967 when he indicated that the \$35-\$40 billion spent on space was worth it because "I know how many missiles the enemy has." In this section we will consider only the satellites using optical instruments, but it should be pointed out that these satellites can also monitor microwave, radiofrequency, active laser, and infrared signals in order to obtain a unique composite picture.

\section{A. Size of objects}

What is the smallest object that one might obtain with a spy satellite under the following assumptions: (1) lens systems with a focal lengths of 3-6 m; (2) satellite altitude of $150 \mathrm{~km}$ (100 miles); and (3) film with grain sizes of about 1 micron and a resolution of about 3 microns $\left(1 \mu=10^{-6} \mathrm{~m}\right)$. (Ignore the limits to resolution by diffraction and by atmospheric seeing until Sec. II B.

Answer: Since the object distance is much greater than the focal length $(o=150 \mathrm{~km}>f=3-6 \mathrm{~m})$, the image distance is approximately equal to the focal length: $f=i$. By similar triangles we can relate the size of the smallest object on the Earth, $h_{0}$, to the image size on the film $h_{i}$, by similar triangles: $h_{0} / o=h_{i} / i$. Inserting the numerical assumptions, the smallest object size on the earth is (ignoring the broadening effects of Sec. II B)

$$
h_{0}=(o)\left(h_{i}\right) / f=\left(1.5 \times 10^{5} \mathrm{~m}\right)(3 \mu) /(3 \mathrm{~m})=15 \mathrm{~cm}(6 \mathrm{in} .)
$$

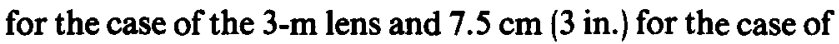
the 6-m lens.

\section{B. Diffraction-limited resolution}

What is the minimum diameter lens size necessary to ensure that the "single slit" diffractive effects are about the same as the film resolution caused by grain sizes of about 1 micron? Because of fluctuations in the atmosphere, astronomers have found that it is very difficult to observe resolutions with optical telescopes much better than about one second of arc. How does the angular resolution limitations from diffraction compare to the resolution limitations caused by atmospheric fluctuations?

Answer: The angular limitations caused by diffraction can be approximated from the case of single slit diffraction where the angle $\theta$ of the first minima is obtained from the formula $(d / 2)(\sin \theta)=\lambda / 2$ where $d$ is the diameter of the slit and $\lambda$ is the wavelength of light. For the case of small angles, we can equate the angle from diffraction to the angular size of the image; $\theta=\lambda / d=h_{i} / f$. The image size obtained from this approach, $h_{i}=f \lambda / d$, is very close to the more accurately obtained diffraction limit obtained for circular lenses, $h_{i}=f \lambda / 0.82 d$. From this we obtain the approximate minimum size of the satellite lens in order to have equal broadening from diffraction and from grain size,

$$
\left.d=\lambda f / 0.82 h_{i}\right)=(0.5 \mu)(3 \mathrm{~m}) /(0.82 \times 3 \mu)=0.6 \mathrm{~m} .
$$

The angular sizes of the diffraction limitation and the image size are

$$
\begin{aligned}
\theta & =\lambda /(0.8 d)=\left(5 \times 10^{-7} \mathrm{~m}\right) /(0.8 \times 0.6 \mathrm{~m}) \\
& =1.0 \times 10^{-6} \mathrm{rad} \\
& =0.2 \text { arcsec. }
\end{aligned}
$$

Since this value is less than 1 arcsec from atmospheric seeing, we might conclude that these resolutions are unattainable. However, since the photos are taken considerably above $(100 \mathrm{~km})$ the atmosphere, the effects of atmospheric seeing should be reduced compared to the case of astronomy since the fluctuating air cells are considerably closer (1 $\mathrm{km})$ to the telescope. If the size of the lens is large, the exposure time can be reduced and the effects of atmospheric seeing will be reduced. In addition, the resolution of photography from spy satellites can be improved by using the following technical improvements: (1) folded optical systems with longer focal lengths; (2) film containing photosensitive molecular dyes with considerably reduced grain sizes; (3) lenses with larger diameters; (4) elliptical satellite orbits with reduced perigees of perhaps $50 \mathrm{~km}$ (for a short time) (5) computational techniques which deconvolute images smeared by diffraction; and (6) computational analysis of multiple exposures of the same object.

\section{ICBM ACCURACY}

If the accuracy of a missile is increased, it follows that the yield necessary to carry out a mission against a hardened military target can be correspondingly reduced. As accuracy increased by a factor of 20 from about 5 miles in 1954 to $1 / 4$ mile in 1970, the U.S. decreased the yield of its warheads by a factor of about 100 from $9 \mathrm{Mt}$ (Titan) to 50$100 \mathrm{kt}$ (Polaris/Poseidon) and 170-335 kt (Minuteman). Thus increased accuracy was the necessary precursor to the deployment of smaller warheads and MIRV. Accuracy can be further improved by using NAVSTAR satellites (Sec. IV), using the locations of stars, and other methods. The newer technologies available to the cruise missile have further increased accuracy to less than $10 \mathrm{~m}$ for the cruise missile. The tradeoff between accuracy and yield can be qualitatively understood by considering the perfect gas law. Since we expect the heat deposited within a sphere of radius $r$ to be proportional to the yield $(Y)$ of the weapon, the temperature rise $(\Delta T)$ should be approximately proportional to the yield: $Y \propto n C(\Delta T)$ where $n$ is the number of moles of air within the sphere and $C$ is the specific heat of air. If we are considering locations reasonably close to the weapon, the temperature rise of the air will be approximately the same as the absolute temperature: $\Delta T \simeq T$. Inserting these relationships into the perfect gas law, we obtain

$$
P V \propto \operatorname{Pr}^{3} \propto n R T \propto Y,
$$

which gives the proportionality $P \propto Y / r^{3}$. This approximate relationship agrees with the more accurate derivation by Brode, ${ }^{7}$ who considered the conservation of energy, mass, and momentum to obtain this result. (The $r$ dependence of the overpressure is $1 / r^{3}$ rather than $1 / r^{2}$ since the width of a strongly compressed region increases proportionally to the distance $r$.) It also agrees with the high-pressure limit (the first term) in the empirical relationship? derived from nuclear testing at the Earth's surface,

$$
\Delta P=14.7 Y / r^{3}+12.8\left(Y / r^{3}\right)^{1 / 2},
$$

where $\Delta P$ is the overpressure in psi, $Y$ is the yield in mega- 
tons, and $r$ is the distance from the detonation in nautical miles. Since accuracy improved by a factor of 20 from 1954 to 1970 , it follows that the yield could have been reduced by a factor of $(20)^{3}=8000$ in order to carry out the same military mission. Since the yield was reduced by only a factor of 100 , the additional effective yield of Minuteman and Polaris must have been dedicated to overcoming hardened missile sites and to increasing the probability of a successful mission. The miniturization of nuclear weapons has also enhanced the ability to destroy surface area (as well as point targets). Since the destruction area $A \propto Y^{2 / 3}$, the area will be increased if the yield is divided (MIRV) among $n$ separate warheads, $Y_{1}=n Y_{n}$. Since the ratio of the areas of destruction is

$$
A_{n} / A_{1}=n Y_{n}^{2 / 3} / Y_{1}^{2 / 3}=n\left(Y_{1} / n\right)^{2 / 3} / Y_{1}^{2 / 3}=n^{1 / 3} \text {, }
$$

the area of destruction will be increased, for the case of $n=10$, by a factor of $10^{1 / 3}=2.15$.

\section{A. Guidance above the flat Earth}

In order to avoid the mathematical complications ${ }^{8}$ from an ICBM's Keplerian elliptical orbit, let us consider the trajectory of an ICBM that follows a parabolic path above a large flat Earth. What is the accuracy of an ICBM which has the following properties: (1) an initial velocity of $v=10^{4} \mathrm{~m} / \mathrm{s} ;(2)$ an uncertainty in the initial velocity of $\Delta v=10^{-5} v=0.1 \mathrm{~m} / \mathrm{s}$ in both the range and tracking directions; (3) an initial vertical angle of $\theta=30^{\circ} \simeq 0.5 \mathrm{rad}$; (4) a vetical alignment error of $\Delta \theta=\left(4 \times 10^{-5}\right)(\theta)=2 \times 10^{-5}$ $\mathrm{rad}$; and (5) an azimuthal alingment error of $\Delta \phi=10^{-5}$ rad. For simplicity, we will shall consider these uncertainties to exist during the launch, rather than at the time when the re-entry vehicle $(R V)$ is separated from the bus of the ICBM.

$$
\begin{aligned}
& \text { Answer: The range of the "flat Earth" ICBM is } \\
& X=v^{2} \sin (2 \theta) / g=\left(10^{4}\right)^{2}\left(\sin 60^{\circ}\right) / 9.8=8800 \mathrm{~km} \text {. }
\end{aligned}
$$

The arrival time for this missile is

$$
t=2 v \sin \left(30^{\circ}\right) / g=(2)\left(10^{4}\right)(0.5) /(9.8)=10^{3} \mathrm{~s} \cong 17 \mathrm{~min},
$$

fairly close to the 25-40 min that it takes an ICBM to travel $9000 \mathrm{~km}$. By taking the differential of $X$ and dividing by $X$, we obtain

$$
\Delta X / X=2(\Delta v / v)+2[\Delta \theta / \tan (2 \theta)]-(\Delta g / g) .
$$

The uncertainty in the range from the uncertainty in the velocity is $(2)\left(10^{-5}\right)(8800 \mathrm{~km})=176 \mathrm{~m}$, and from the uncertainty in the vertical alignment is $(2)\left(2 \times 10^{-5}\right)(8800$ $\mathrm{km}) / \tan \left(60^{\circ}\right)=203 \mathrm{~m}$. In addition, we must take into account the error in the tracking direction (the transverse direction) caused by the misalignment of the azimulthal angle,

$$
\Delta Y=(\Delta \phi)(v)(t)=\left(10^{-5}\right)\left(10^{4} \mathrm{~m} / \mathrm{s}\right)\left(10^{3} \mathrm{~s}\right)=100 \mathrm{~m} .
$$

Since the effects of these errors will add randomly, it is appropriate to determine their root-mean-square value in the range, or $\sigma_{r}=\left(176^{2}+203^{2}\right)^{1 / 2}=269 \mathrm{~m}$. Combining this with the error in tracking we obtain $\sigma=\left(269^{2}\right.$ $\left.+100^{2}\right)^{1 / 2}=287 \mathrm{~m}=0.16 \mathrm{~nm}$. If the range term was reduced by a factor of 3 , to $90 \mathrm{~m}, \sigma$ would drop to 134 $\mathrm{m}=0.07$ nautical miles. For comparison sake, the new MX missile is intended to have an accuracy of about $100 \mathrm{~m}$ ( 0.05 nautical miles) and the cruise missile has been shown to have an accuracy of better than $5 \mathrm{~m}$ after traveling 300 miles (with continuous guidance). The last term in the equation $(\Delta g / g)$ is the bias error term; this is discussed in Sec. VII.

\section{B. Rotating flat Earth}

If the vertical velocity is too large by an amount $\Delta v_{z}=\left(10^{-5}\right)(v)=0.1 \mathrm{~m} / \mathrm{s}$, the missile will fall to the west of the target since the Earth has rotated an additional distance eastward during the extra time of flight. How large is this effect at the equator?

Answer: The error in the vertical velocity will increase the time of flight by $\Delta t=2\left(\Delta v_{z}\right) / g=(2)(0.1) /(9.8)=0.02$ s. Since the Earth moves $0.44 \mathrm{~km} / \mathrm{s}$ at the equator, this effect will cause the missile to fall to the west by about $\Delta X=v \Delta t=0.44 \mathrm{~km} / \mathrm{s})(0.02 \mathrm{~s})=9 \mathrm{~m}$. This value is about a factor of 3 less than the published value of $30 \mathrm{~m} /(0.1 \mathrm{~m} / \mathrm{s})$ for elliptical orbits. Since the error is somewhat less than the errors discussed above, we can ignore this contribution.

\section{MX basing mode}

One of the many issues raised in the discussion of the MX missile is the type of basing mode that might be used such as the "race track" shelters (vertical or horizontal), "dense pack," hardened Minuteman silos, or submarine based. Since it takes a relatively small overpressure of about 5 psi to destroy an ordinary brick house and it takes a significantly larger pressure of 2000 psi to destroy a hardened, $H$, Minuteman silo, it is clear that the choice of basing mode is relevant to the survivability of the MX to a first-strike attack. Determine the approximate accuracy that would be necessary to destroy the MX shelter by an attacking missile under these conditions: (1) the incoming missile has a yield of 0.75 megatons; and (2) the MX is stored either in a horizontal "race track" shelter which is hardened to withstand about $H=600 \mathrm{psi}$, in a hardened Minuteman silo $(H=2000$ psi), or a superhardened silo ( $H=5000$ psi or more).

Answer: The accuracy needed $(r)$ to develop $600 \mathrm{psi}$ from a $Y=0.75 \mathrm{Mt}$ bomb is obtained from

$$
H=600 \mathrm{psi}=(14.7)\left(0.75 / r^{3}\right)+(12.8)\left(0.75 / r^{3}\right)^{1 / 2},
$$

which gives $r=0.28$ nautical miles $=510 \mathrm{~m}$. For the case of $H=2000$ psi we obtain $r=0.18$ nautical miles $=335$ $\mathrm{m}$; and for $H=5000$ psi we obtain $r=0.13$ nautical miles $=245 \mathrm{~m}$. These results imply that there is a diminishing return for the hardening of missile sites since hardening the silo from 2000 to 5000 psi only required improving the accuracy from 0.18 to 0.13 nautical miles. The ultimate hardening would be determined from the maximum radius of the crater from the $0.75 \mathrm{Mt}$ warhead which is about $r \cong 160 Y^{0.3}=140 \mathrm{~m}$ for the case of the silo in a rock medium (170 $\mathrm{m}$ in dry soil). It is clear that the vulnerability of the MX system, or any system, is much more complicated (see Sec. VII) than this simple example as one must consider launch reliablity; the effect of the EMP on the $C^{3}$ systems; the ability to determine the occupancy of an MX shelter by thermal, acoustic, or optical sensors; the use of decoys in shelters; fratricide effects (the destruction of an incoming missile by another incoming missile); degradation of theoretical performance standards; the inability to test such a theoretical option; and the survivability of other systems such as bombers, submarines, tactical weapons, and cruise missiles. 


\section{Dense Pack}

It has been proposed to base the MX missile in a very closely packed matrix so that incoming missiles would destroy each other (fratricide). If the nearest-neighbor distance is $545 \mathrm{~m}(1800 \mathrm{ft})$, determine the minimum value of the hardness ( $H$ in psi) of the MX silos that would prevent the incoming warheads $(Y=0.75,1,5$, and $25 \mathrm{Mt})$ from destroying more than one MX silo. Consider the incoming warheads to be accurately placed so that they land on the surface, equidistance from two silos. (Accuracy of missiles will be considered in Sec. VII.)

Answer: Since the nearest-neighbor spacing is $545 \mathrm{~m}$, an incoming warhead that was located halfway between two silos would be $273 \mathrm{~m}$ from each silo. Using the formula for overpressure from surface blasts (Sec. III C), we obtain the following values: $H>3500$ psi for $0.75 \mathrm{Mt}$ warheads; $H>5000$ psi $(1 \mathrm{mT})$; and $H>22000$ psi (5 Mt); and $H>110000 \mathrm{psi}(25 \mathrm{Mt})$. In addition, one must consider the size of the craters from these warheads; if the radius of the crater $^{5,7}$ is greater than $273 \mathrm{~m}$, then both silos could be destroyed. By using the Rand Corporation's "Bomb Damage Effect Computer" (1964), we have obtained the radii of the craters in rock: $r=142 \mathrm{~m}(0.75 \mathrm{Mt}), r=158 \mathrm{~m}(1 \mathrm{Mt})$, $r=279 \mathrm{~m}(5 \mathrm{Mt})$, and $r=485$ ( $25 \mathrm{Mt})$. By using more resilient rock media it is possible to reduce these radii somewhat, but it is clear that a very large warhead would create a large enough crater to envelope two MX silos. (There is some recent evidence that these crater radii should be reduced by a factor of about 2 .)

\section{NAVSTAR GLOBAL POSITIONING SATELLITES}

The United States is developing the NAVSTAR ${ }^{10}$ system of orbiting satellites which would be used to enhance the accuracy of cruise missiles, antiship missiles, glide bombs, or heavy missiles. Twenty-four orbiting satellites would be located in nongeosynchronous orbits about 11000 miles above the Earth. The missiles would determine their positions by comparing the time delays and Doppler shifts of the signals from several satellites. Since a cruise missile using the NAVSTAR guidance system would not broadcast radar signals to determine its location, but would only receive and analyze signals from satellites to make midcourse guidance corrections, the NAVSTAR system would diminish the vulnerability of the cruise missile. The proponents of the system claim that NAVSTAR would be viable for both high- and low-altitude approaches and for "launch and leave" tactics that would allow the launching aircraft to withdraw as soon as the missile is fired; the opponents claim that the NAVSTAR signal could be jammed and that the NAVSTAR satellites are soft targets that could be destroyed easily.

\section{A. Guidance by delay times}

Using triangulation, estimate the approximate accuracy in position available to a cruise missile system that had the following characteristics: (1) NAVSTAR orbits are 17700 $\mathrm{km}$ above the Earth's surface and $24150 \mathrm{~km}$ above the center of the Earth; (2) the 24 NAVSTAR satellites are in equally spaced equatorial orbits; (3) the cruise missile follows trajectories less than $1 \mathrm{~km}$ above the Earth's surface; and (4) the cruise missile can measure time differences of

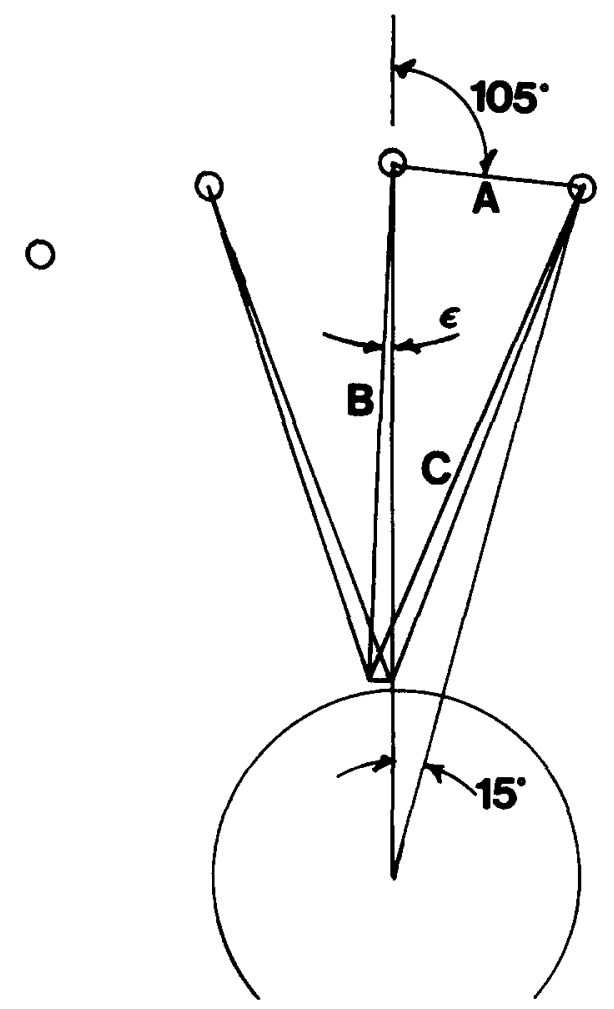

Fig. 2. NAVSTAR global positioning satellites could increase the accuracy of missiles in two ways. By monitoring the time differences of radio signals from several NAVSTAR satellites, it would be possible to triangulate the position of the missile to, perhaps, less than $10 \mathrm{~m}$ in three dimensions. By also monitoring the history of the Doppler shifts of the signals from several NAVSTAR's, it should be possible to determine the velocity of the missile to, perhaps, less than $1 \mathrm{~cm} / \mathrm{s}$. As the missile moves ahead $1 \mathrm{~m}$ in its orbit, the side $C$ increases by $0.35 \mathrm{~m}$; this movement creates a time delay of $2.4 \mathrm{~ns}$ between the signals from the NAVSTAR satellites closest to the zenith satellite. This movement of $1 \mathrm{~m}$ makes the angle $\epsilon=5.6$ $\times 10^{-8} \mathrm{rad}$; this angle would cause a Doppler shift of about $0.1 \mathrm{~Hz}$ from a 100-GHz NAVSTAR signal.

about $1 \mathrm{~ns}$ between the signals from different NAVSTAR satellitess.

Answer: For simplicity, let us consider the cruise missile to be directly under one of the NAVSTAR satellites. The signals from the first neighbor satellites $\left(360^{\circ} / 24=15^{\circ}\right)$ on either side of the satellite in the zenith position) will arrive at the cruise missile at the same time. (See Fig. 2.) First of all, let us determine the distance $C$ between the cruise missile and the first neighbor NAVSTAR. Since we will be using the differential form of the law of cosines, it will not be necessary to carry out trigonometric calculations to nine significant figures. Consider a triangle with side $A$ as the chord between the zenith satellite and its first neighbor, side $B$ as the distance between the zenith satellite and the cruise missile $(17700 \mathrm{~km})$, and side $C$. The chord length $A=2 R \sin \left(7.5^{\circ}\right)$ where $R$ is $24150 \mathrm{~km}$, the distance from center of the Earth to a NAVSTAR satellite; we obtain $A=6304 \mathrm{~km}$. Since we know the length of sides $A$ and $B$, and the outside angle between these sides $\left(105^{\circ}\right)$, the distance between the the first neighbor satellites and the cruise missile is

$$
C=\left[A^{2}+B^{2}+2 A B \cos \left(105^{\circ}\right)\right]^{1 / 2}=17184 \mathrm{~km} \text {. }
$$

If the cruise missile moves forward in its orbit $1 \mathrm{~m}$ with respect to its former position directly under the zenith NAVSTAR, there will be a delay time between the pulses 
from the two first-neighbor NAVSTAR's. Since the 1-m shfit will increase the distance $B$ by only one part in $10^{14}$, we will consider both $B$ and $A$ as constants. The change in $C$ is thus mainly caused by the change in the angle between $A$ and $B$ which is $\tan (\epsilon) \cong \epsilon=0.001 \mathrm{~km} / 17700 \mathrm{~km}=5.6$ $\times 10^{-8} \mathrm{rad}=3.2 \times 10^{-6} \mathrm{deg}$. The distances from the two nearest-neighbor satellites to the cruise missile can be determined directly from the law of cosines by adding (and subtracting) the angle $\epsilon$ from the $105^{\circ}$ angle; or, more easily, by taking the differential of the law of cosines, $(A$ and $B$ are effectively constant)

$$
C_{f}-C_{i}=\Delta C=A B \epsilon \sin \left(105^{\circ}\right) / C=0.35 \mathrm{~m} \text {. }
$$

The time delay between the two nearest-neighbor NAVSTAR pulses will be $(2 \times 0.35 \mathrm{~m}) /\left(3 \times 10^{8} \mathrm{~m} / \mathrm{s}\right)=2.4 \mathrm{~ns}$ which is much larger than the inaccuracy from hydrogen maser atomic clocks $\left(10^{-13}\right)$ and quartz clocks which are being considered for NAVSTAR. A more accurate treatment of this problem would have to take into account the 57-ms transit time of the pulses and the relative velocities of the two satellites. If the computer in the cruise missile is able to take into account these factors, then, perhaps, the NAVSTAR system might be able to determine locations on their trajectories to within, perhaps, $10 \mathrm{~m}$ in three dimensions.

\section{B. Guidance by Doppler shifts}

Estimate the change in the Doppler shift of a $100-\mathrm{GHz}$ signal from a NAVSTAR as an ICBM missile passes directly under the NAVSTAR in the zenith position to $1 \mathrm{~m}$ beyond the zenith position.

Answer: The velocities of the NAVSTAR and the ICBM are determined from $v=(G M / r)^{1 / 2}$ where $G=6.673$ $\times 10^{-11} \mathrm{~N} \mathrm{~m}^{2} / \mathrm{kg}^{2}, M$ is the mass of the Earth $\left(5.983 \times 10^{24}\right.$ $\mathrm{kg}$ ), and the radius $r$ is $24150 \mathrm{~km}$ for NAVSTAR and 6450 $\mathrm{km}$ for the ICBM. We obtain $v=4066 \mathrm{~m} / \mathrm{s}$ for the NAVSTAR and $v=7868$ for the ICBM missile. Their relative velocity is $3802 \mathrm{~m} / \mathrm{s}$ (when they move in the same direction) and $11934 \mathrm{~m} / \mathrm{s}$ (when they move in the opposite direction). Since we can ignore the relativistic transverse Doppler shift at these velocities, there will be no Doppler shift when the ICBM is exactly in the zenith position. When the ICBM moves forward by $1 \mathrm{~m}$ with respect to the zenith position, the $100-\mathrm{GHz}$ signal will be shifted by

$$
\begin{aligned}
\Delta f & =f(v / c) \sin (\epsilon)=\left(10^{11}\right)\left(3802 / 3 \times 10^{8}\right)\left(5.6 \times 10^{-8}\right) \\
& =0.071 \mathrm{~Hz}
\end{aligned}
$$

when they travel in some direction and $\Delta f=0.22 \mathrm{~Hz}$ when they travel in the opposite direction. In addition it can be readily shown that a $1-\mathrm{m}$ movement in the position of the ICBM will also shift the signal from the neighboring NAVSTAR satellites by about $0.1 \mathrm{~Hz}$. Presumably, by measuring the various beat frequencies available to the ICBM, it should be possible to determine positions on the trajectory from the history of the Doppler shift measurements to less than tens of meters. (Or the velocity to, perhaps, $1-10 \mathrm{~cm} / \mathrm{s}$ using the position data from time delays in Sec. IV A.)

\section{PARTICLE AND LASER BEAM WEAPONS}

The superpowers are currently developing weapons that would utilize the kinetic energy (in the $\mathrm{GeV}$ range) of particle beams or the energy content of laser beams to destroy incoming missiles, surface cruise missiles, ships, or satel- lites. The particle- and laser-beam weapons might be mounted on the surface of the Earth, in the space shuttle, or on satellite stations in space. These weapons have to be described as futuristic since there are many technological obstacles that must be overcome before they would become operational. In addition, these weapons would be vulnerable to countermeasures by the attacking force. These weapon systems have been described ${ }^{11}$ in some detail by Tsipis $e t$ $a l$. , and we will discuss only their more general properties.

\section{A. Energy deposition}

What flux of energy $\left(\mathrm{J} / \mathrm{cm}^{2}\right)$ would be necessary to preignite the chemical explosives around a nuclear weapon in the incoming missile? Following Tsipis et al. assume that a temperature rise of $500^{\circ} \mathrm{C}$ can preignite the explosive material which has a density of $\rho=0.8 \mathrm{~g} / \mathrm{cm}^{3}$ and a molecular weight of about $M=50$. In addition, assume that the absorption length for $1 \mathrm{GeV}$ electrons is about $10 \mathrm{~cm}$; the beam loses about $10 \%$ of its energy in $1 \mathrm{~cm}$. How much would this flux of energy raise the temperature of the aluminum body of the missile?

Answer: The energy density needed to predetonate the chemical explosive is $Q=C \rho \Delta T / M$ where the $\Delta T$ is the temperature rise and the specific heat $C=3 R=25 \mathrm{~J} / \mathrm{mo}-$ le ${ }^{\circ} \mathrm{C}$ (since $T>\theta_{D}$, the Debye temperature). We obtain

$$
Q=(3 R) p \Delta T / M=(25)(0.8)(500) / 50=200 \mathrm{~J} / \mathrm{cm}^{3} \text {. }
$$

Since about $10 \%$ of the energy is deposited in $1 \mathrm{~cm}$, the energy intensity of the beam must be about $2000 \mathrm{~J} / \mathrm{cm}^{2}$ in order to deposit $200 \mathrm{~J} / \mathrm{cm}^{3}$ in the chemical explosive. This same flux of energy would raise the temperature, $\Delta T$, of the aluminum missile:

$$
Q=200 \mathrm{~J} / \mathrm{cm}^{3}=(3 R p \Delta T / M=(25)(2.7)(\Delta T) / 27,
$$

which gives $\Delta T=80^{\circ} \mathrm{C}$. This modest temperature rise would begin to cause some internal stresses and misalignment in the missile. Doses about eight times larger (16000 $\mathrm{J} / \mathrm{cm}^{2}$ and $1500 \mathrm{~J} / \mathrm{cm}^{3}$ ) would raise aluminum to its melting temperature of $660^{\circ} \mathrm{C}$. In addition, the particles can cause havoc with the semiconducting components in the guidance systems; energy densities as low as $25 \mathrm{~J} / \mathrm{cm}^{3}$ can cause shifts in the switching thresholds of the circuit elements and $1000 \mathrm{~J} / \mathrm{cm}^{3}$ can destroy the elements. The energetic particles could create centers for trapping, and recombination which would reduce the lifetime of the minority carriers.

\section{B. Beam current and angular resolution}

What minimum beam current of $1 \mathrm{GEV}$ electrons would be necessary to preignite the chemical explosive in the incoming missile? Assume that the size of the beam is dictated by the $1-\mathrm{m}$ diameter of the missile booster and that the pulse duration is determined by the velocity of the missile, $v=10^{4} \mathrm{~m} / \mathrm{s}$. What angular accuracy $(\Delta \theta)$ would be required to disable a missile which is $1000 \mathrm{~km}$ away and above the atmosphere?

Answer: Using the energy intensity of $2000 \mathrm{~J} / \mathrm{cm}^{2}$ from Sec. V A, the energy delivered to an area of $1 \mathrm{~m}^{2}$ (dictated by the diameter of the missile) is $\left(2000 \mathrm{~J} / \mathrm{cm}^{2}\right)\left(10^{4}\right.$ $\left.\mathrm{cm}^{2}\right)=2 \times 10^{7} \mathrm{~J}$. In order to keep the area of the beam on the missile for a single shot without continuous tracking, the time duration of the pulse must be less than $t=(1 \mathrm{~m} /$ $\left.10^{4} \mathrm{~m} / \mathrm{s}\right)=0.1 \mathrm{~ms}$. The energy in the pulse is $V I t=2 \times 10^{7}$ $\mathrm{J}$ where $V=10^{9} \mathrm{~V}$ and $I$ is the current in amperes. Solving 
for $I$, we get

$$
I=\left(2 \times 10^{7}\right) / V t=\left(2 \times 10^{7}\right) /\left(10^{9}\right)\left(10^{-4}\right)=200 \mathrm{~A} .
$$

If the beam was intended to melt aluminum or destroy semiconducting components, the current and energy of the beam must be at least five times higher, or $1000 \mathrm{~A}$ and $10^{8} \mathrm{~J}$. It has been estimated that the efficiency of producing a pulse of particles is about $1 / 6$, thus it takes about $6 \times 10^{8} \mathrm{~J}$ to make the 1000-A pulse. Since it takes abot $0.9 \mathrm{lb}$ of coal to generate $\mathrm{a} \mathrm{kW} \mathrm{h}=3.6 \times 10^{6} \mathrm{~J}$, it would take about $150 \mathrm{lb}$ of coal (or $1000 \mathrm{lb}$ of TNT) to generate one pulse; the large amount of any type of fuel would certainly complicate the logistics of placing either particle- or laser-beam weapons on a space station. For comparison sake there are already existing high-voltage, low-current accelerators, such as the Fermilab's proton accelerator which has a current of 0.1 $\mathrm{mA}$ at an energy of $500 \mathrm{GeV}$, and there are low-voltage, high-current electron accelerator used in the fusion program which have a current of $10^{6} \mathrm{~A}$ (per beam) at an energy of $2 \mathrm{MeV}$. Because the Earth's magnetic field will deflect long-range, charged particle beams, a beam of neutral hydrogen atoms (produced from $\mathrm{H}^{-}$beams passing through a stripper gas) might be considered. The present technology is not yet capable of these requirements as the Los Alamos Meson Factory is capable of developing currents of only $0.15 \mathrm{~A}$ of $\mathrm{H}^{-}$ions at $1 \mathrm{GeV}$.

In order to "shoot a bullet $1000 \mathrm{~km}$ away with a bullet," the beam must be aligned to within an accuracy of $\Delta \theta=1$ $\mathrm{m} / 10^{6} \mathrm{~m}=10^{-6} \mathrm{rad}$. Since this kind of accuracy would be difficult to carry out, it is likely that the beam current would have to be correspondingly increased to compensate for a larger spread in beam size at the target. If $\Delta \theta \simeq 10^{-5}$, the current and total energy of the beam would have to be increased by a factor of 100 ; if the target was considerably closer, this would not be necessary.

\section{Burning a hole in the atmosphere}

Since relativistic electrons and protons of about $1 \mathrm{GeV}$ lose about $0.2 \mathrm{GeV} / \mathrm{km}$ when they pass through air, they would not be able to penetrate through the entire atmosphere. Particle beam weapons that were located on the surface of the Earth would have to be able to "burn a hole in the atmosphere" in order to reduce energy losses and make the weapon viable over longer distances. If the air density in the "hole" in the atmosphere was reduced by a factor of 10 , then the energy loss rate would be reduced to 0.02 $\mathrm{GeV} / \mathrm{km}$, and the beam would then lose about $0.2 \mathrm{GeV}$ (20\% of the beam energy) to pass through the entire atmosphere of $10 \mathrm{~km}$. Approximately how much energy would it take to reduce the density of the air by a factor of ten in a "hole" that had an area of $1 \mathrm{~cm}^{2}$ and was $1 \mathrm{~km}$ long? The density of air is $1.3 \mathrm{~kg} / \mathrm{m}^{3}$ and its specific heat at constant pressure is $1000 \mathrm{~J} / \mathrm{kg}^{\circ} \mathrm{C}$.

Answer: Using the perfect gas law, $P V=n R T$, we see that the temperature must be raised from about 300 to 3000 $\mathrm{K}$ in order to allow a reduction in the density, $n / V$, by a factor of 10. The mass of the heated air in the atmospheric hole is $\left(1.3 \mathrm{~kg} / \mathrm{m}^{3}\right)\left(10^{3} \mathrm{~m}\right)\left(10^{-4} \mathrm{~m}^{2}\right)=0.13 \mathrm{~kg}$. The amount of energy required to heat the "hole" is

$$
Q=m C \Delta T=(0.13)(1000)(2700)=3.5 \times 10^{5} \mathrm{~J} \text {. }
$$

Additional energy would be lost by the partial heating of the air forced out of the hole, by the loss of scattered radiation and secondary particles, and by turbulance. Our value of $0.4 \times 10^{6} \mathrm{~J} / \mathrm{km}$ is a lower bound value and it is about
$25 \%$ of the more accurately calculated ${ }^{11}$ value of $1.5 \times 10^{\circ}$ $\mathrm{J} / \mathrm{km}$. This energy loss is about $1 \% / \mathrm{km}$ of the beams energy of $10^{8} \mathrm{~J} ;$ a $10-\mathrm{km}$ path would use $10 \%$ of the beam's energy; this is similar to the energy that would be lost by the beam as it passed through the hole. At this time it is unclear how long the high-energy beam would remain in the hole over these extended distances.

\section{Laser-beam weapons}

Either a $25-\mathrm{kJ}$ pulse laser or a $1-\mathrm{MW}$ continuous laser is capable of destroying nearby aircraft. However, since laser beams do not readily pass through fog or rain, the laserbeam weapons could not be counted on to defend against a surprise attack on a rainy day. For this reason, the laserbeam weapons (if they are ever deployed) would probably be used above the atmosphere. Determine the necessary energy for a laser pulse to destroy a missile $1000 \mathrm{~km}$ away using these assumptions: (1) it takes a pulse of about $1000 \mathrm{~J} /$ $\mathrm{cm}^{2}$ (Sec. V A above) to create an impulsive failure in thin metal targets such as missiles; (2) the $\mathrm{CO}_{2}$ laser has a wavelength $\lambda=10.6 \mu \mathrm{m}$; and (3) the beam extraction mirror of the laser has a diameter $d=3 \mathrm{~m}$.

Answer: The finite diameter of the extraction mirror causes a diffraction broadening in the laser beam

$$
\begin{aligned}
\Delta \theta & =1.22 \lambda / d=(1.22)\left(10.6 \times 10^{-6} \mathrm{~m} / 3 \mathrm{~m}\right) \\
& =4.3 \times 10^{-6} \mathrm{rad} .
\end{aligned}
$$

This effect will broaden the radius of the laser beam 1000 $\mathrm{km}$ away to

$$
r=(\Delta \theta)(1000 \mathrm{~km})=4.3 \mathrm{~m} \text {. }
$$

Since it takes about $1000 \mathrm{~J} / \mathrm{cm}^{2}$ of absorbed energy to partially melt and crack the missile body, the energy in the laser pulse must be $\left(1000 \mathrm{~J} / \mathrm{cm}^{2}\right)(\pi)(430 \mathrm{~cm})^{2}=5.8 \times 10^{8} \mathrm{~J}$ for the case of total absorption, and ten times this for the case of $10 \%$ absorption of the laser beam. This energy requirement is considerably larger than the presently contemplated 25-kJ pulsed lasers being developed for the fusion program. If the weapon was a 1-MW continuous laser, then the laser would have to be focused on the target for

$$
t=\left(5.8 \times 10^{8} \mathrm{~J}\right) /\left(10^{6} \mathrm{~J} / \mathrm{s}\right)=580 \mathrm{~s} \cong 10 \mathrm{~min} \text {, }
$$

which is one of the reasons that very large HF lasers are now being explored.

\section{THE NEUTRON BOMB}

Because the yield of a neutron bomb ${ }^{12}$ is approximately equally divided between the fission and fusion processes, it produces many more neutrons (that are also much more energetic than the neutrons from a pure fission tactical weapon). It is for this reason that the neutron bomb is also referred to as the enhanced-radiation weapon (ERW). The deployment of the neutron bomb in Europe has been a controversial issue for several reasons: On the one hand, it has been encouraged because some feel that we will not use our present tactical weapons to stop an invasion of conventionally armed tanks because the yield of our present tactical weapons is too large (some are greater than $20 \mathrm{kt}$, but some also that can be reduced with a dial to about $1 \mathrm{kt}$ ). These leaders want the neutron bomb because a 1-kt version would be able to incapacitate tank crews at a distance of about $850 \mathrm{~m}$ compared to $375 \mathrm{~m}$ for a pure fission weapon of the same yield. They argue that it would destroy about five times as many tanks for about the same amount of blast 
damage to the countryside of an ally. The proponents of the neutron bomb feel that the mere possession of it would increase the perception of the potential invader that we would actually use it, and thus it would deter an invasion. On the other hand, it can be envisioned that the use of this type of a tactical weapon would lower the psychological and bureaucratic threshold for the decision makers to use nuclear weapons, and thus its deployment would increase the probability that there would be a precursor to a more general nuclear war that nobody wants. The opponents of the neutron bomb do not believe that the neutron bomb would actually incapacitate that many tank crews because the invading forces would space the tanks further apart in order to negate the effects of the neutron bomb.

\section{A. Number of neutrons}

Determine the approximate numbers of neutrons at a distance of $800 \mathrm{~m}$ from weapons that derive their energy from (1) pure fission, (2) pure fusion, and (3) $50 \%$ each of fission and fusion. Assume the following: (1) the weapons have a yield of $1 \mathrm{kt}=10^{12} \mathrm{cal}=4.2 \times 10^{12} \mathrm{~J} ;(2)$ initially, ignore the scattering of the fast neutrons by the atmosphere; (3) the energy of fission is about $200 \mathrm{MeV}$ and the energy from fusion $\left(\mathrm{H}^{2}+\mathrm{H}^{3} \rightarrow \mathrm{He}^{4}+\mathrm{n}\right)$ is $17.6 \mathrm{MeV}$; and (4) the chain reaction from a fission weapon yields about one surplus neutron.

Answer: The yield of a $1-\mathrm{kt}$ weapon is $\left(4.2 \times 10^{12} \mathrm{~J}\right)(1 \mathrm{eV} /$ $\left.1.6 \times 10^{-19} \mathrm{~J}\right)=2.6 \times 10^{31} \mathrm{eV}$. If one assumes that one of the three neutrons from a fission event is used to sustain the chain reaction and one is absorbed in the weapon, then one neutron/fission will escape from the weapon. The number of neutrons that escape from a 1-kt fission weapon is about

$$
\begin{aligned}
n & =\left(2.6 \times 10^{31} \mathrm{eV}\right)\left(1 \text { neutron } / 2 \times 10^{8} \mathrm{eV}\right) \\
& =1.3 \times 10^{23} \text { neutrons. }
\end{aligned}
$$

the number of neutrons from a 1-kt pure fusion weapon would be about

$$
\begin{aligned}
n & =\left(2.6 \times 10^{31} \mathrm{eV}\right)\left(1 \text { neutron } / 17.6 \times 10^{6} \mathrm{eV}\right) \\
& =1.5 \times 10^{24} \text { neutrons, }
\end{aligned}
$$

which is about a factor of 10 greater than the result for the fission weapon. Since a fusion weapon needs the heat from the fission precursor, it is necessary to have a mixed fission/fusion weapon to make a neutron bomb. For the case of $50 \% / 50 \%$, we obtain $8.2 \times 10^{23}$ neutrons which is about six times the number of neutrons from a comparable fission weapon. [The number of neutrons per kiloton can also be increased by removing the "tamper" (or jacket) material on the outside of the weapon.]

Neglecting the scattering of the fast neutrons by the atmosphere, we obtain the integrated neutron flux at $800 \mathrm{~m}$ as follows:

$$
\begin{aligned}
n / \text { area } & =1.3 \times 10^{23} /(4 \pi)\left(8 \times 10^{4} \mathrm{~cm}\right)^{2} \\
& =1.6 \times 10^{12} \text { neutrons } / \mathrm{cm}^{2}
\end{aligned}
$$

for the case of the fission weapon and $10^{13}$ neutrons $/ \mathrm{cm}^{2}$ for the neutron bomb. Because of scattering and absorption by the atmosphere and other uncertainties, these values for the neutron fluxes are about two to three times greater than the experimental ${ }^{13}$ values. (The fluxes actually drop more quickly, closer to $r^{-4}$ than $r^{-2}$. Brode ${ }^{7}$ indicates that the exponential function $e^{-r / \rho}$ can be used.)

\section{B. Radiation dosages}

If a person receives a dose of about 8000 rads (1 $\mathrm{rad}=100 \mathrm{erg} / \mathrm{g}$ ), he or she will be incapacitated within a period of about $5 \mathrm{~min}$ and will die within a day or two. If a 1-kt fission bomb will deliver about 250 rads of neutrons at a distance of $800 \mathrm{~m}$, what approximate dosage level would the neutron bomb deliver at the same distance? What is the approximate ratio of radioactive fallout from the neutron bomb and the fission bomb?

Answer: The radiation dosage from the neutron bomb would be considerably greater than a fission bomb of the same yield because it produces about six times more neutrons and each neutron is bout seven times more energetic $(14 \mathrm{MeV} / 2 \mathrm{MeV}=7)$. Thus one would expect the neutron bomb to deliver an instantaneous dosage of about (250 rads) (6) (7) $\cong 10000$ rads, which is enough to incapacitate a person within about $5 \mathrm{~min}$. Since the fission process produces much more radioactivity than the fusion process, the neutron bomb (which is $50 \%$ fission) will produce about $50 \%$ as much radioactive fallout as the pure fission bomb.

\section{Reduced blast}

About $50 \%$ of the yield of a fission weapon appears in the form of blast energy which can destroy buildings. For the case of a fusion bomb, the blast contribution is only $20 \%$. How much less area would be destroyed by a blast from a neutron weapon than from a fission weapon?

Answer: The blast energy (BE) for the fission weapon is $0.5 \mathrm{kt}$ and for the neutron bomb it is about $(0.5+0.2) /$ $2=0.35 \mathrm{kt}$. Since the destruction area is approximately proportional to $(\mathrm{BE})^{2 / 3}$ (see Sec. III), the ratio of destruction area from the neutron bomb to that of the fission bomb is $A_{n} / A_{f}=(0.35 / 0.5)^{2 / 3}=0.79$. This result indicates that the destruction area from the use of the neutron bomb would be about $21 \%$ less than the destruction area of a fission bomb of the same yield. Combining this result with the increased area for neutron dosages, one obtains a neutron radiation area from the neutron bomb which is about $(800 \mathrm{~m} / 375 \mathrm{~m})^{2} /(0.79)$ or six times greater for the same blast area from the fission bomb.

\section{WAR GAMES}

In this section we shall briefly discuss some simplified models for "war games" that have been discussed in the literature. These models have allowed the participants in the debates on the arms race to compare widely diverse missile systems in order to prove their debating points. Perhaps ultimately, one can not use equations and parameters to describe the "action-reaction" escalation of the arms race, and the degree of stability from mutually assured destruction (MAD), but it is also true that these mathematical models do give some meaningful insights into the interactions that affect the outcomes of these difficult questions. The results of the this section should be properly modified to account for the many uncertainties in the arms race: (1) the debris (EMP, wind, ionized atmosphere, dust particles) from an incoming missile can negate a second incoming missile (the fratricide effect), or prevent the launching of the missile in the silo from being launched (the pin-down effect); (2) the uncertainty in the parameters of the missile systems will complicate any numerical analysis; this is particularly true for the reliability of these complex systems; (3) since the Partial Test Ban treaty (PTB) prevents any 
rehearsal of a preemptive first strike, no attacker can be sure that the intricate timing and coordination of events will actually be successful; (4) the uncertain locations of submarines missile systems, bombers, cruise missiles, mobile missiles, and tactical weapons will further complicate any discussion of a "first strike in a war game"; and (5) either side may have strategies and hardware that are unknown to the other side.

\section{A. Lethality parameter}

During the testimony on the SALT II treaty before the U.S. Senate, the lethality parameter $K$ was used to discuss the various U.S. and U.S.S.R. missile systems. It was defined as $K=Y^{2 / 3} / \mathrm{CEP}^{2}$, where $Y$ is the yield of the weapon in megatons and CEP is the accuracy (the circular error probable) of the weapon in nautical miles. The CEP is defined as the radius of the circle centered in the pattern which contains $50 \%$ of the missiles which were launched. The center of this pattern can be shifted from the aim point by bias errors (which may, or may not, be included in the definition of CEP). Why would the testimony on SALT II use the $K$ parameter? In our calculations we will assume that the testimony was ony dealing with the silo-busting, high-pressure regime of small distances from the silo where one considers only the first term in the pressure relationship (Sec. III). Let us speculate on the general form (following Tsipis's derivation ${ }^{14}$ ) of the single-shot-kill-probability (SSKP) formula if one considers that the accuracy of the individual missiles are randomly spread about the aim point with a normal Gaussian distribution such that the probability of survival is

$$
P_{s}=e^{-r_{s}^{2} / 2 \sigma^{2}},
$$

where the survival radius $r_{s}$ is the minimum distance from the silo that a weapon of yield $Y$ can explode without destroying the silo. The standard deviation of the distribution is $\sigma$ and assume that it is proportional to CEP; Tsipis has shown that $\sigma=0.85 \mathrm{CEP}$. Assume that the silo is hardened to withstand a pressure of $H$ psi before it is destroyed.

Answer: The minimum pressure to destroy a missile silo is $H=\Delta P \propto Y / r^{3}$. The area in which the silo could be destroyed is proportional to ${ }_{S}^{2} \propto(Y / H)^{2 / 3}$. The area that contains $50 \%$ of the missile landings is proportional to CEP ${ }^{2}$. The ratio of the area of destruction to the area of accuracy is proportional to $Y^{2 / 3} / \mathrm{CEP}^{2}$ which is defined as the lethality $K$. This definition contains only the parameters of the incoming missile without mentioning the degree of hardening of the silo. By multiplying $K$ by the MIRV number $n$ and the number of missiles of that category, $m$, one can obtain the lethality of a class of missiles, $n m K$. By summing over all the classes of missiles, one obtains the grand total lethality of a nation's arsenal. This procedure has been used in the testimony before the Congress and elsewhere. ${ }^{14}$ The discussion on lethality can be misleading in that a warhead can have a very large lethality, but it still can destroy at most only one silo.

It follows that the single-shot kill probability for a missile is of the form

$$
P_{k}=1-P_{s}=1-e^{-r_{s}^{2} / 2 \sigma^{2}}=1-e^{-Y^{2 / 3} / B H^{2 / 3} \mathrm{CEP}^{2}},
$$

where Tsipis has shown that $B=0.22$ when $Y$ is in megatons, $H$ is in psi, and CEP is in nautical miles. Using the definition of lethality, this formula becomes

$$
P_{k}=1-e^{-K / 0.22 H^{2 / 3}} \text {. }
$$

\section{B. Minuteman vulnerability}

The uncertainties that we described in the introduction to this section indicate that a simple calculation of the vulnerability of the Minuteman force is more complicated than the formulas that we have developed in Sec. VII A. In addition, the retaliatory aspects of the submarines, bombers, and tactical weapons can act as a deterrent if one were to wish to take advantage of whatever vulnerability the Minuteman force has. Determine the SSKP of destroying a Minuteman silo assuming the following parameters ${ }^{9,14}$ : (1) Minuteman silos are hardened to about $H=2000$ psi; (2) the Russian SS-18 warheads have a yield $Y=0.75$ megatons and a CEP $=0.15$ nautical miles (at some point in the future); and (3) the reliability $R$ of an SS18 is, perhaps, 0.8 , or 0.9 . What is the kill probability for a silo if two SS-18 weapons from different launchers are aimed at the Minuteman silo?

Answer: The lethality of the SS-18 warhead is $K=(0.75)^{2 / 3} / 0.15^{2}=36.7$. The SSKP for the SS-18 on a Minuteman silo is

$$
P_{k}=1-e^{-36.7 /(0.22)(2000)^{2 / 3}}=1-0.35=0.65 \text {. }
$$

The SSKP should be multiplied by the reliability of the SS18 to obtain the success rate for each SS-18 warhead; we obtain $52 \%$ for $80 \%$ reliability, and $59 \%$ for $90 \%$ reliability. For the case of two SS-18 weapons from different launchers (arriving less than about $10 \mathrm{~s}$ apart to avoid fratricide effects), the kill probability is $P_{k 2}=1-(0.48)^{2}$ $=77 \%$ for $80 \%$ reliability and $83 \%$ for $90 \%$ reliability. Because of fratricide effects, it is likely that at most two SS18 's would be targeted at one Minuteman silo, one in the air and one on the ground. Nevertheless, for the case of three independent SS-18's, $P_{k 3}=1-(0.48)^{3}=89 \%$ (for the case of $80 \%$ reliability). Since there are 1000 Minuteman missiles, these results imply that perhaps 170 to 230 would survive two SS-18's, and 100 would survive three SS-18's. The latter case would consume the entire SS-18 force since there are about 308 SS-18 launchers and each is MIRVed ten times. Since neither side has projected missiles over the North Pole, this discussion may not consider the additional bias error ${ }^{15}$ ( $\Delta g / g$ term, Sec. III A) from the intended target caused by uncertainties in the Earth's gravitational field. Since the polar radius of the Earth is $21 \mathrm{~km}(0.3 \%)$ smaller than its equatorial radius, the quadrupolar correction to $g$ should be of the order of $(\Delta g / g) \cong 10^{-3}$, or 100 times larger than the ratio of $(C E P /$ range $)=\left(10^{-1} \mathrm{~km} / 10^{4}\right.$ $\mathrm{km})=10^{-5}$. It follows that the corrections for the multipolarity and the local gravity at the launch site must be carried out to within about $1 \%$ accuracy in order to prevent degradation of the CEP accuracy of the missile.

As we have shown, the probability of destroying a missile site depends on many parameters $(Y, \mathrm{CEP}, H, R$, and gravitational bias error). It is possible to determine the relative importance of changes in these parameters by taking the differential of the total single-shot kill probability TK which takes into account the reliability $R$ of the missile system:

$$
\mathrm{TK}=R P_{k}=R\left(1-e^{-\alpha}\right),
$$

where $\alpha=K /\left(0.22 H^{2 / 3}\right)=Y^{2 / 3} / 0.22 \mathrm{CEP}^{2} H^{2 / 3}$. It follows that

$$
\begin{aligned}
\Delta T K / T K & =\Delta R / R+(2 \alpha / 3)(\Delta Y / Y-\Delta H / H \\
& -3 \Delta \mathrm{CEP} / \mathrm{CEP}) /\left(e^{\alpha}-1\right) .
\end{aligned}
$$


For the case of an SS-18 attacking Minuteman, we have used $Y=0.75 \mathrm{Mt}, H=2000 \mathrm{psi}, \mathrm{CEP}=0.15$ (in 1985?), $R=0.8$ to $0.9, K=36.7$, and $\alpha=1.0506$. If we allow the parameters $(Y, H, \mathrm{CEP}$, and $R)$ to vary by $10 \%$, we find that a $10 \%$ increase in yield $(\Delta Y / Y=0.1)$ will increase TK by $3.8 \%(\Delta \mathrm{TK} / \mathrm{TK}=0.038)$. Similarily, $\mathrm{TK}$ can be increased by $10 \%$ by increasing reliability by $10 \%$; TK can be increased by $11.3 \%$ by decreasing CEP by $10 \%$; and TK can be decreased by $3.8 \%$ by increasing hardness by $10 \%$. From this it is clear, that reliability and CEP are the most sensitive variables.

\section{Richardson model}

The literature contains a variety of mathematical models ${ }^{16}$ that attempt to describe various aspects of the arms race. A physicst, Lewis Richardson, was one of the first (1919) to attempt a significant model ${ }^{17}$ of the arms race based on the statistics of past wars. His model considered the action-reaction response of one nation to the threat of increased military spending by its adversary. The two-nation model uses the coupled differential equations

$$
\begin{aligned}
& \dot{x}=k y+a x+g, \\
& \dot{y}=1 x+b y+h,
\end{aligned}
$$

where $x$ and $y$ are the armament levels of the two nations, and $a, b, k, l, g$, and $h$ are parameters. What is the significance of the various terms in these equations? What signs would you expect for the various parameters? Derive a sufficient condition for the parameters which would ensure a stable condition between the two adversaries.

Answer: The first terms on the right in the equations are the "threat," or "reaction" terms and they represent the pressure on one nation to increase its armaments when its neighbor has armaments that can threaten its existence. Since the "defense coefficients" are positive $(k$ and $l>0)$, the arms race would be exponentially unstable if we considered only the first terms in the equations.

The second terms are the "economic burden" terms; the finiteness of labor, capital, and resources of a nation will reduce the predicted production rate of armaments. Since these "fatigue" or "expense" coefficients are negative $(a$ and $b<0)$, it is possible to have some stability in the arms race.

The third terms are the constant "grievance," or "ambition" terms; the coefficients $g$ and $h$ are positive when the nations are dissatisfied and negative when they are satisfied.

The condition for stability is determined by solving the first equation for $y$ and then substituting $y$ and its derivative $(\dot{y})$ into the second equation; we obtain

$$
\ddot{x}-(a+b) \dot{x}+(a b-k l) x=h k-b g .
$$

Depending on the magnitude (and sign) of the parameters, the result can be analogous to the differential equation for a damped spring and mass system in a gravitational field. Since both $a$ and $b<0$, the $\dot{x}$ term will damp out the oscillatory solutions. If $a b>k l$, the arms race will have stable oscillations, and if $a b<k l$, the arms race will be unstable. In Richardson's analysis of these equations, he added the coordinates $x$ and $y$ in order to utilize normal coordinate solutions.

'D. Hafemeister, Am. J. Phys. 41, 1191 (1973); 42, 625 (1974); 44,86 (1976); 47, 671 (1979); 48, 112 (1980); 50, 29 (1982); 50, 713 (1982).

${ }^{2}$ W. Panofsky, Phys. Today 34, 32 (June 1981); Progress in Arms Control?, edited by B. Russet and B. Blair (Freeman, San Francisco, 1979); Arms Control, edited by H. York (Freeman, San Francisco, 1973).

${ }^{3}$ D. Schroeer and J. Dowling, Am. J. Phys. 50, 786 (1982).

${ }^{4}$ E. Woollett, Am. J. Phys. 48, 104 (1980).

${ }^{5} \mathrm{~S}$. Glasstone and P. Dolan, The Effects of Nuclear Weapons (Dept. of Defense and Dept. of Energy, Washington, D.C., 1977), Chaps. 8 and 11; W. Broad, Science 212, 1009, 1116, 1248 (1981); L. Ricketts, Fundamentals of Nuclear Hardening of Electronic Equipment (Wiley, New York, 1972); L. Ricketts, J. Bridges, and J. Milletta, EMP Radiation and Protective Techniques (Wiley, New York, 1976).

${ }^{6}$ T. Greenwood, Sci. Am. 228, 14 (Feb. 1973).

${ }^{7}$ M. Brode, Ann. Rev. Nucl. Sci. 18, 153 (1968).

${ }^{8} \mathrm{D}$. Hoag, in Impact of New Technologies on the Arms Race, edited by $\mathrm{B}$. Feld, T. Greenwood, G. Rathjens, and S. Weinberg (MIT, Cambridge, MA, 1971), p. 19.

${ }^{9} M X$ Missile Basing (Office of Technology Assessment, Washington, D.C., 1981).

${ }^{i 0}$ R. Garwin, Bull. At. Sci. 37, 48 (May 1981).

${ }^{11}$ G. Bekefi, B. Feld, J. Parmentola, and K. Tsipis, Nature 284, 219 (1980); J. Parmentola and K. Tsipis, Sci. Am. 240, 54 (April 1979); M. Callaham and K. Tsipis, High Energy Laser Weapons: A Technical Assessment (Program in Science and Technology for International Security, MIT, Cambridge, MA, 1980); K. Tsipis, Sci. Am. 245, 51 (Dec. 1981).

${ }^{12}$ F. Kaplan, Sci. Am. 238, 44 (May 1978).

${ }^{13}$ S. Glasstone and P. Dolan, The Effects of Nuclear Weapons (Dept. of Defense and Dept. of Energy, Washington, DC, 1977), p. 366.

${ }^{14}$ K. Tsipis, Science 187, 393 (1975); 206, 510 (1979).

${ }^{15}$ E. Marshall, Science 213, 1230(1981). R. E. Anderson, Bull. At. Sci. 37, 6 (Nov. 1981); W. Kaula, Theory of Satellite Geodesy (Blaisdell, Waltham, MA, 1966); M. Caputo The Gravity Field of the Earth (Academic, New York, 1967).

${ }^{16} \mathrm{~T}$. Saaty, Mathematical Models of Arms Control and Disarmament (Wiley, New York, 1968); J. Gillespie and D. Zinnes, Mathematical Systems in International Relations Research (Praeger, New York, 1977).

${ }^{17}$ L. Richardson, Arms in Insecurity and Statistics of Deadly Quarrels (Boxwood, Pittsburgh, 1960); F. Lanchester, Engineering 98, 422 (1914). 